11,12

\title{
Образование новых структурных состояний в прессованных нанопорошках $\mathrm{BaTiO}_{3}$
}

\author{
(ㄱ И.М. Шмытько, Д.Д. Фролов, А.С. Аронин, Г.Р. Ганеева, В.В. Кедров \\ Институт фризики твердого тела РАН, \\ Черноголовка, Россия \\ E-mail: shim@issp.ac.ru
}

(Поступила в Редакцию 6 июня 2016 г.

В окончательной редакции 7 декабря 2016 г.)

\begin{abstract}
Методами рентгеновской дифрактометрии, электронной сканирующей и просвечивающей микроскопии, а также дифференциальной калориметрии исследованы изменения структуры нанокристаллического порошка $\mathrm{BaTiO}_{3}$ и таблеток, полученных из этого порошка, после последующих высокотемпературных отжигов на воздухе. Показано, что, начиная с температуры отжига, равной $T=1200^{\circ} \mathrm{C}$, в таблетках наряду с фазой $\mathrm{BaTiO}_{3}$ образуется значительное количество фазы $\mathrm{Ba}_{2} \mathrm{TiO}_{4}$. Эта фаза является равновесной — при понижении температуры отжига до $700-600^{\circ} \mathrm{C}$ она практически исчезает, а при повторном повышении температуры отжига до $1200^{\circ} \mathrm{C}$ восстанавливается фактически до исходного состояния. Отжиги порошкообразных образцов к образованию новых фазовых состояний не приводят. С отжигом растет только размер их кристаллитов. Обсуждается вероятная причина появления в таблетках фазы $\mathrm{Ba}_{2} \mathrm{TiO}_{4}$ и ее отсутствие в свободных порошках.
\end{abstract}

DOI: $10.21883 /$ FTT.2017.06.44490.230

\section{1. Введение}

Хорошо известно, что структурные и физические характеристики нано- и микрокристаллических объектов могут кардинально отличаться друг от друга. Наши предыдущие исследования структуры простых и сложных оксидов редкоземельных элементов в нанокристаллическом состоянии выявили целую серию структурных эффектов, которые были неизвестны для этих оксидов в микрокристаллическом состоянии [1-17]. Два из них следующие: 1) формирование core-shell структуры в отдельных нанокристаллитах, образующихся на первых этапах кристаллизации из аморфного прекурсорного состояния $[4,5,7,13] ; 2)$ циклические перестройки атомной структуры с ростом размера кристаллитов при изменении температуры для соединений, имеющих несколько фаз в микрокристаллическом состоянии. Оба эти эффекта мы объясняли повышенной энергией поверхностных атомов (shell) по отношению к внутренним атомам (core) и увеличением доли поверхностной энергии с уменьшением размера кристаллитов $[1,11,14]$.

Мы продолжили исследования влияния дополнительной поверхностной энергии на образование новых структурных состояний в наноразмерных системах, неизвестных для микроразмерных систем. Для этой цели мы исследовали образцы нанопорошков, спрессованых в таблетки. В этом случае изменение энергии системы происходит за счет разницы энергии межкристаллитных границ и поверхностной энергии отдельных кристаллитов. Кроме того, в этом случае нульмерная система $(0 D)$ из отдельных кристаллитов переходит в $3 D$-систему для таблеток, в которой все кристаллиты контактируют между собой, что изменяет ее статистические харак- теристики. Последнее в свою очередь может влиять на поведение такой системы при изменении размера кристаллитов.

Были исследованы структурные состояния $\mathrm{Y}_{2} \mathrm{O}_{3}$, $\mathrm{Gd}_{2} \mathrm{O}_{3}$ и $\mathrm{Eu}_{2} \mathrm{O}_{3}$ в нанопорошках и после прессования их в таблетки в зависимости от температуры и времени отжига [17]. Было показано, что, начиная с некоторого размера и структурного качества кристаллитов, которые определялись температурой и временем отжига исходного нанопорошка, дополнительный высокотемпературный отжиг таблеток (спрессованных при нагрузке, равной $6.4 \cdot 10^{3} \mathrm{~kg} / \mathrm{cm}^{2}$ ) приводил к появлению в них новых структурных состояний. Для $\mathrm{Gd}_{2} \mathrm{O}_{3}$ и $\mathrm{Eu}_{2} \mathrm{O}_{3}$ эти новые фазы имели структуру известных для этих соединений высокотемпературных фаз, но в таблетках из нанокристаллитов они образовывались при значительно более низких температурах. Последующие дополнительные отжиги таких таблеток, сопровождающиеся ростом кристаллитов, приводили к исчезновению этих фаз. Для $\mathrm{Y}_{2} \mathrm{O}_{3}$ новая фаза, образовавшаяся после компактирования в таблетки, вообще была ранее неизвестна для этого соединения. Эти результаты показали, что энергия межкристаллитных границ оказывает существенное влияние на структурные состояния наносистем из простых оксидов РЗМ.

Задача настоящего исследования - подтвердить общность наблюдаемого явления, заключающегося в значительном влиянии межкристаллитных границ в наноскопических системах на их структурные состояния. Для этой цели аналогичные эксперименты были проведены для практически важного соединения, а именно сегнетоэлектрика $\mathrm{BaTiO}_{3}$, нанопорошки которого широко используются для получения сегнетоэлектрических керамик. Согласно базе данных PDF-2, для титаната 
бария известно 5 фаз. Это низкотемпературная ромбоэдрическая фаза с пространственной группой симметрии S.G. $R 3 m$ (160) $\left(a=4.004 \AA, \alpha=89.87^{\circ}\right)$, которая образуется ниже $-97^{\circ} \mathrm{C}$; орторомбическая фаза с пространственной группой симметрии S.G. Amm2 (38) $(a=3.9806 \AA, b=5.671 \AA, c=5.6904 \AA)$, существующая в интервале $\sim-97-+2{ }^{\circ} \mathrm{C}$; тетрагональная фаза (S.G. P4mm (99), $a=3.994 \AA, c=4.038 \AA$ ), существующая в интервале $2-123^{\circ} \mathrm{C}$; кубическая фаза (S.G. Pm-3m (221), $a=4.0577 \AA$ ), существующая в интервале $123-\sim 1460^{\circ} \mathrm{C}$; и, наконец, высокотемпературная гексагональная фаза (S.G. P63/mmc (194), $a=3.994 \AA, c=4.038 \AA)$, образующаяся при температуре $\sim 1460^{\circ} \mathrm{C}[18]$. Такая последовательность фаз давала надежду на то, что как и в простых оксидах РЗМ, в таблетках произойдет образование высокотемпературной фазы в межкристаллитных границах при заведомо более низких температурах, нежели в порошках. Однако результат оказался совсем неожиданным.

\section{2. Образцы и методы исследования}

Для выполнения поставленной задачи использовались промышленные порошки $\mathrm{BaTiO}_{3}$ (ТУ 6-09-3963-84, VEKTON). Размеры кристаллитов изменялись посредством изотермических отжигов порошков на воздухе при температурах $400,500,600^{\circ} \mathrm{C}$ и т. д. в лабораторной печи SNOL-6.7/1300 по следующей схеме: нагрев до конечной температуры отжига в течение 1.5-3h и выдержка при температуре отжига в течение 3.5-5h. После отжига образцы вынимались из печи для быстрого охлаждения на воздухе, после чего проводились рентгеноструктурные исследования при комнатной температуре.

Компактирование образцов осуществлялось медленным сжатием порошка до величины 5 тонн в цилиндрической ячейке диаметром $10 \mathrm{~mm}\left(6.4 \cdot 10^{3} \mathrm{~kg} / \mathrm{cm}^{2}\right)$ на установке INSTRON. После достижения максимальной нагрузки образец выдерживался под нагрузкой в течение $5 \mathrm{~min}$, после чего быстро разгружался.

Структурное состояние образцов изучалось с помощью рентгеновского дифрактометра D500 (Siemens), использовалась геометрия Брэгг-Брентано и $\mathrm{Cu}-K_{\alpha}$ излучение. Определение среднего размера кристаллитов и „, $a^{\text {“ }}$ и „,“ параметров тетрагональной ячейки осуществлялось с помощью приближения Вильямсона-Холла [19]. Для этой цели использовались порядки отражений типа $(h 0 l)$ и $(h h h)$. Отражения $(h 0 l)$ позволяли определить уровень тетрагональности кристаллитов $c / a$, отражения $(h h h)$ использовались для определения среднего размера кристаллитов, поскольку остаются монорефлексами независимо от симметрии фазы титаната бария. Для получения неискаженного профиля указанных дифракционных рефлексов, который определяет точность измерения структурных параметров, первые 3 щели гониометра, формирующие падающий и дифрагированный пучки в гониометре, имели расходимость $0.3^{\circ}$. Четвертая щель перед рентгеновским детектором составляла $0.018^{\circ}$. Шаг углового сканирования гониометра равнялся 0.02 градуса. Такое соотношение геометрических параметров сканирования и регистрации рефлексов позволяло определять максимальные размеры кристаллитов свыше $100 \mathrm{~nm}$ (до $150 \mathrm{~nm}$ ).

Морфология и химический состав образцов изучались с помощью сканирующей электронной микроскопии (SEM) на микроскопе SUPRA II. Изучение топологической структуры отдельных кристаллитов $\mathrm{BaTO}_{3}$ осуществлялось с помощью просвечивающей электронной микроскопии (ТЕМ) на электронном микроскопе JEM-100CX.

Для определения температур фазовых переходов в зависимости от размера кристаллитов использовалась дифференциальная сканирующая калориметрия (DSC). Калориметрические исследования осуществляли на дифференциально-сканирующем калориметре Perkin Elmer DSC-7, с использованием программного обеспечения Polaris. Масса навески составляла $\sim 10-15 \mathrm{mg}$, а скорость нагрева равнялась $\approx 20 \mathrm{~K} / \mathrm{min}$. Исследования проводили в протоке аргона.

\section{3. Результаты экспериментов и обсуждения}

3.1. Структурные изменения в нанопорошках $\mathrm{BaTiO}_{3}$. На рис. 1, $a$ показано SEM-изображение исходного порошка титаната бария. Хорошо видно, что основным топологическим элементом структуры являются сферические частицы размером порядка 100-120 nm, которые состоят из более мелких частиц со средним размером $\sim 30-50 \mathrm{~nm}$. Дифракционный спектр исходного состояния порошка титаната бария показан на рис. $1, b$. Визуально все рефлексы на спектре не расщеплены на какие-либо компоненты, что характерно для кубической фазы $\mathrm{BaTiO}_{3}$. Однако использование приближения Вильямсона-Холла для рефлексов $(h 0 l)$ и $(h h h)$ показало, что исходное состояние относится к тетрагональной фазе с параметрами решетки $a=b=4.005 \AA, c=4.011 \AA$ и средним размером кристаллитов $\langle D\rangle \approx 115 \mathrm{~nm}$. Сравнение полученных результатов с SEM-изображением на рис. 1, $a$ указывает на сильное различие размеров кристаллитов, определенных рентгеновскими методами и сканирующей электронной микроскопией.

На рис. 2 приведены темнопольное $(a)$, светлопольное $(b)$ ТЕМ-изображения и картина микродифракции $(c)$ индивидуальной шарообразной частички исходного состояния нанопорошка. Видно, что, как и в случае сканирующей микроскопии, шарообразная частица состоит из набора более мелких субзерен, что подтверждает вывод о том, что шарообразные частицы (и на SEM-, и на ТЕМ-изображениях) действительно состоят из нанокристаллитов размером $\sim 30-50 \mathrm{~nm}$.

Для объяснения сильного различия среднего размера кристаллитов, полученного из электронно-микроскопических данных, от среднего размера, полученного из рентгенографических данных, можно предложить две 
модели. Первая модель предполагает, что кристаллические решетки в субзернах шарообразной частицы имеют относительно малые разориентации, что в дифрактометрическом эксперименте отображается как дифракция от единого кристаллита. Вторая модель - это широкая дисперсия размеров, при которой объем крупных кристаллитов превышает объем мелких. В этом случае в дифракционном эксперименте полуширина рефлексов будет определяться крупными кристаллитами, а мелкие кристаллиты будут отображены в крыльях этих рефлексов. Эти две модели объединяются, если предположить, что шарообразная частица может состоять из преобладающего крупного зерна, состоящего из более мелких субзерен с малыми разориентациями, и небольшой доли более мелких кристаллитов с большой разориентацией между собой. Это, в частности, наблюдается на микродифрактограмме рис. 2, $c$, на которой виден набор интенсивных пятен с преимущественной ориентацией и набор „случайных пятен“ малой интенсивности. Более того, часть рефлексов преимущественной ориентации имеет расщепления на компоненты, отображающие малые разориентации субзерен внутри основного кристаллита.

Дальнейшие отжиги исходного порошка по описанной выше методике при температурах 200, 400, 500, 600,

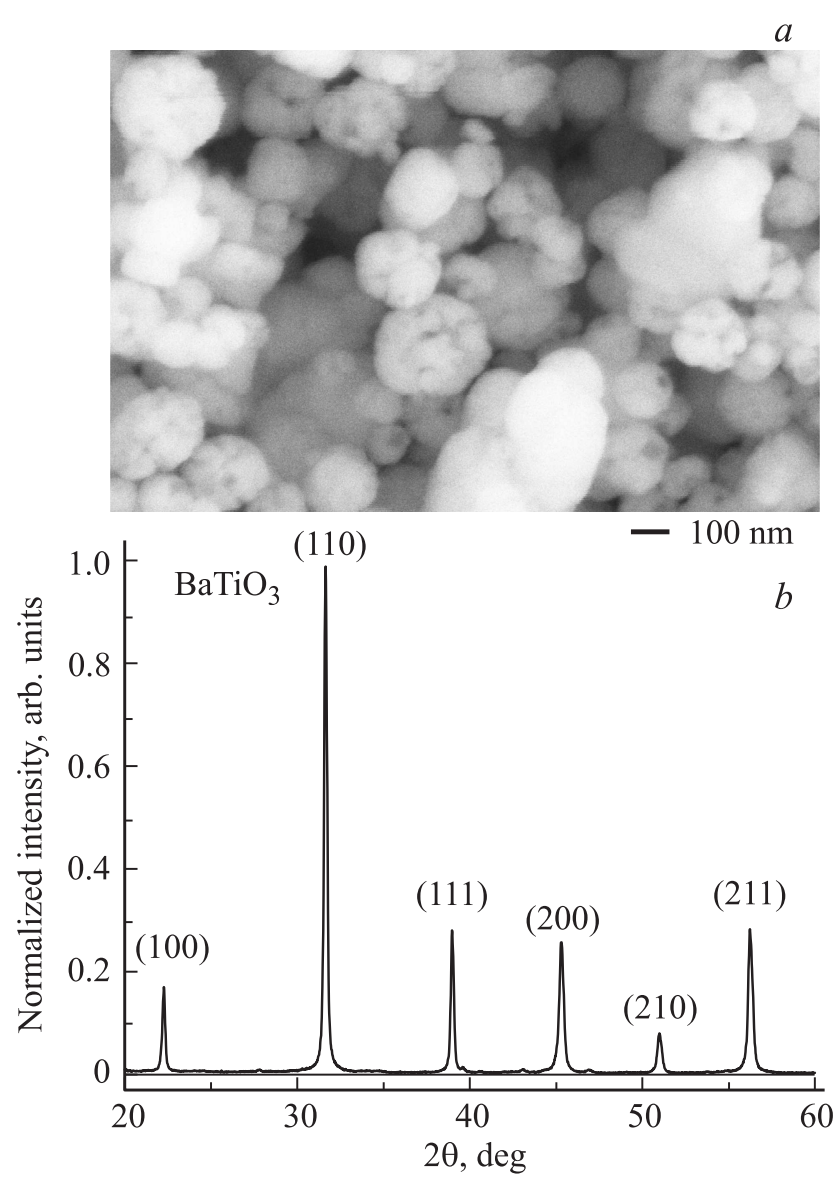

Рис. 1. (a) - SEM-изображение исходного состояния порошка $\mathrm{BaTiO}_{3}$ при комнатной температуре; $(b)-$ рентгеновский дифракционный спектр исходного состояния порошка $\mathrm{BaTiO}_{3}$.
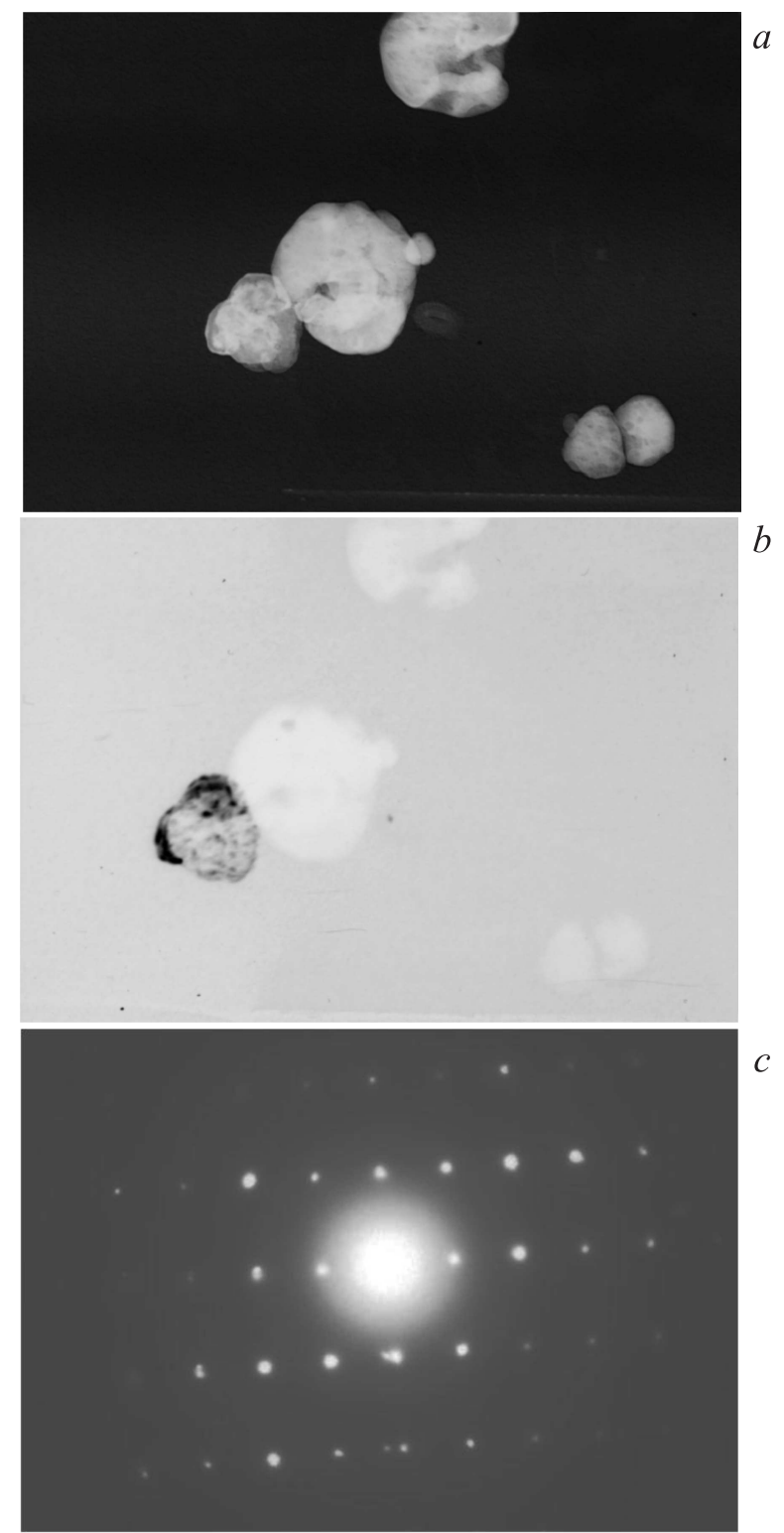

Рис. 2. ТЕМ-изображения отдельного кристаллита исходного порошка $\mathrm{BaTiO}_{3}$. (a) - светлопольное изображение; $(b)$ - темнопольное изображение; $(c)$ - микродифракционный снимок.

700 и $800^{\circ} \mathrm{C}$ показали, что такой отжиг фактически не приводит к изменению SEM-изображений отдельных частиц. В качестве подтверждения на рис. 3 показано SEM-изображение порошка после соответствующего отжига при температуре $800^{\circ} \mathrm{C}$. Рентгеновские спектры, однако, показывают, что средний размер кристаллитов с увеличением температуры отжига растет, но незначительно. Незначительно изменяются и параметры тетрагональной ячейки (см. рис. 4).

Калориметрические исследования на тех же самых образцах показали, что для таких образцов калориметрические кривые имеют вид, характерный для размытых фазовых переходов. На рис. 5 показана детальная 


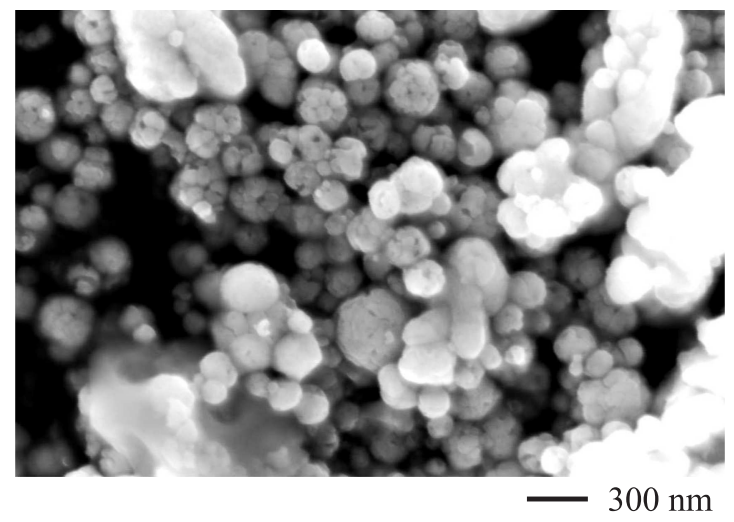

Pис. 3. SEM-изображения порошка $\mathrm{BaTiO}_{3}$, отожженного в течение $5 \mathrm{~h}$ при $800^{\circ} \mathrm{C}$.

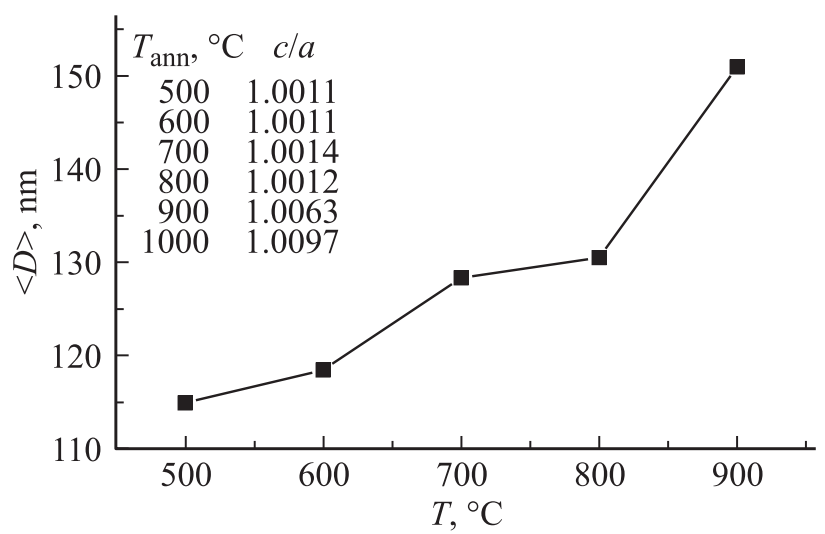

Рис. 4. Средний размер кристаллитов $\mathrm{BaTiO}_{3}$ после изотермических отжигов исходного порошка в течение $5 \mathrm{~h}$ при соответствующих температурах.

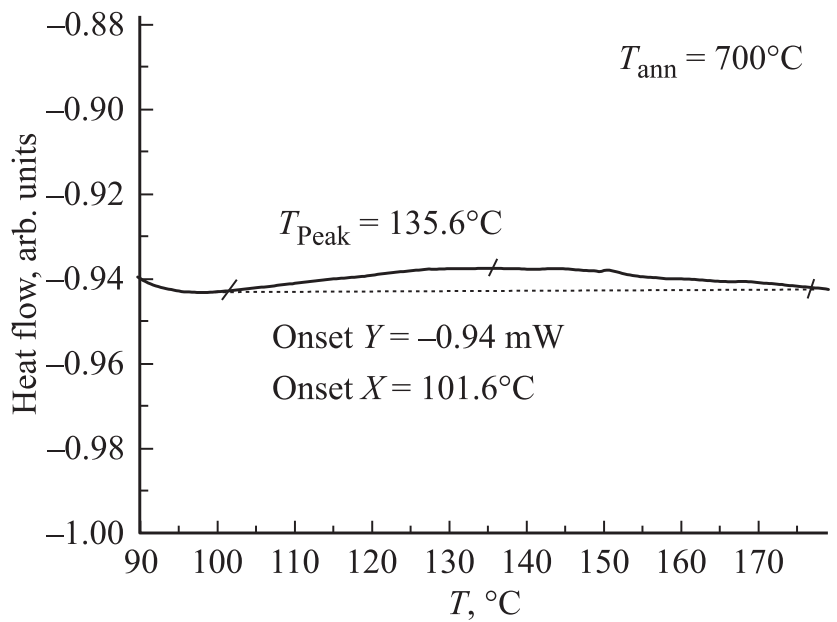

Pис. 5. Детализированная DSC-кривая, полученная от исходного порошка титаната бария, отожженного при температуре $700^{\circ} \mathrm{C}$ в течение $5 \mathrm{~h}$.

DSC-кривая для температуры отжига, равной $700^{\circ} \mathrm{C}$, обработанная по программе Polaris. Хорошо видно, что интервал фазового перехода из кубической модификации в тетрагональную модификацию распространяется от $\sim 102^{\circ} \mathrm{C}$ до $175^{\circ} \mathrm{C}$ и даже далее. Одновременно температура фазового перехода, если за нее принять пиковое значение DSC-кривой, равная в нашем случае $135.6^{\circ} \mathrm{C}$, перемещается в область более высоких температур по сравнению с температурой фазового перехода для макрокристаллического состояния, равной $\sim 123^{\circ} \mathrm{C}$.

Первое заметное изменение SEM-изображения наблюдалось при изотермическом отжиге исходного порошка при температуре отжига порошка, равной $900^{\circ} \mathrm{C}$ (см. рис. 6). Согласно рисунку, это изменение связано с образованием отдельных кристаллитов с выраженной огранкой. Появление огранки кристаллитов сопровождается на рентгеновских дифрактограммах расщеплением (хотя и незначительным) отражений типа $(h 00)$ псевдокубической фазы на компоненты $(h 00)$ и $(00 l)$ тетрагональной фазы. Одновременно на DSC-кривой проявляется, хотя и слабый, но достаточно узкий пик, соответствующий температуре фазового перехода, известной для микроскопических порошков. Для температуры отжига, равной $1000^{\circ} \mathrm{C}$, DSC-кривая (см. рис. 7) соответствует известным кривым для макропорошков титаната бария.

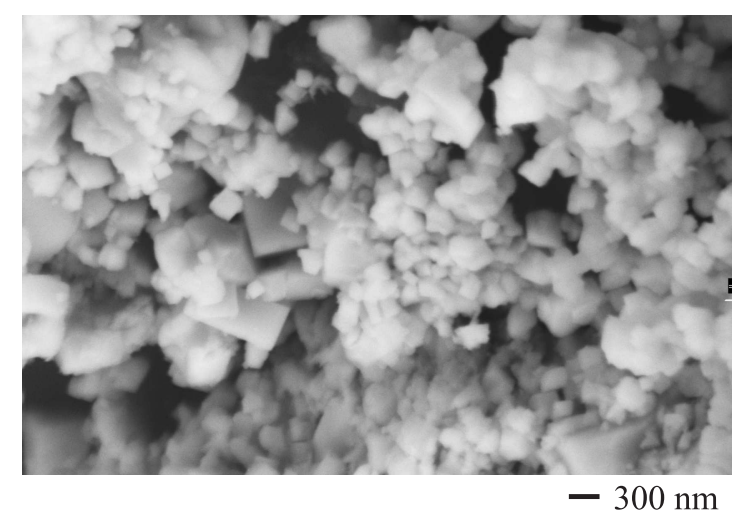

Рис. 6. SEM-изображение порошка $\mathrm{BaTiO}_{3}$, отожженного при температуре, равной $900^{\circ} \mathrm{C}$, в течение $5 \mathrm{~h}$.

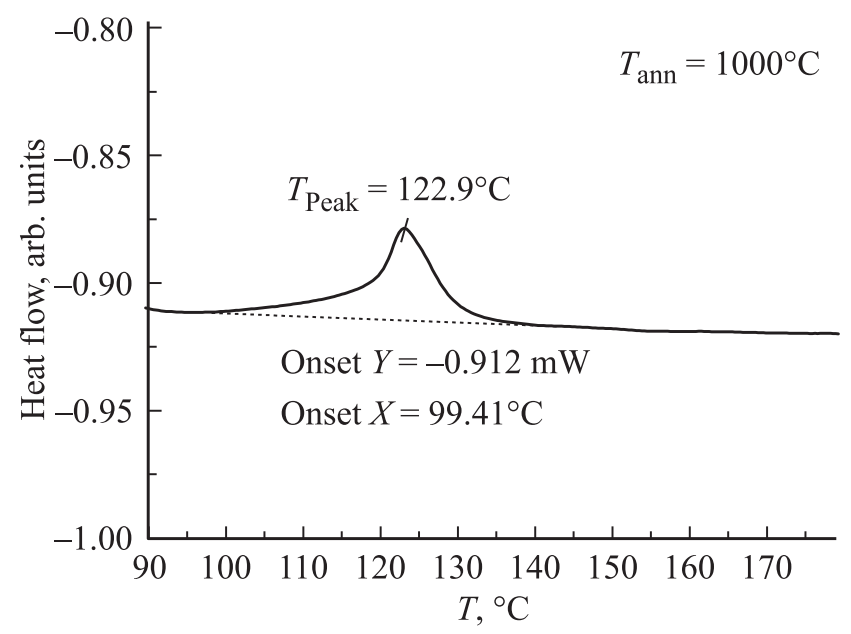

Рис. 7. Детализированная DSC-кривая, полученная от исходного порошка титаната бария, отожженного при температуре $1000^{\circ} \mathrm{C}$ в течение $5 \mathrm{~h}$. 
Этой температуре отжига соответствует образец, в котором все кристаллиты приобрели выраженную огранку (см. рис. 8).

Возникает вопрос: чем обусловлено изменение температуры и ширины фазового перехода из кубической фазы в тетрагональную, отображаемых на DSC-кривых, при увеличении температуры отжига исходного нанопорошка титаната бария? Можно предположить, что это, с одной стороны, обусловлено изменением размера кристаллитов, а с другой - повышением совершенства структуры отдельных кристаллитов (характеризуемого, например, образованием огранки). На возможность влияния размера кристаллитов на температуру и интервал фазового перехода указывалось еще в работе [20]. Для установления природы изменения температуры и ширины фазового переходы мы отожгли исходный порошок при достаточно низкой температуре, равной $400^{\circ} \mathrm{C}$, в течение длительного времени $(16 \mathrm{~h})$, предполагая, что при таком отжиге разрастания кристаллитов не произойдет, а совершенство структуры значительно улучшится. Результат такого эксперимента показан на рис. 9 и 10. На SEM-изображении видно, что сложные шарообразные кристаллиты исходного порошка (см. рис. 1) трансформировались в однородные по

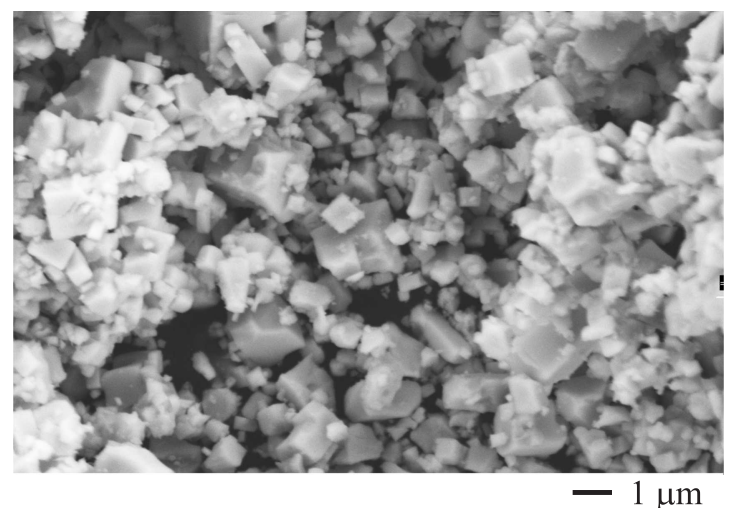

Pис. 8. SEM-изображение порошка $\mathrm{BaTiO}_{3}$, отожженного при температуре, равной $1000^{\circ} \mathrm{C}$, в течение $5 \mathrm{~h}$.

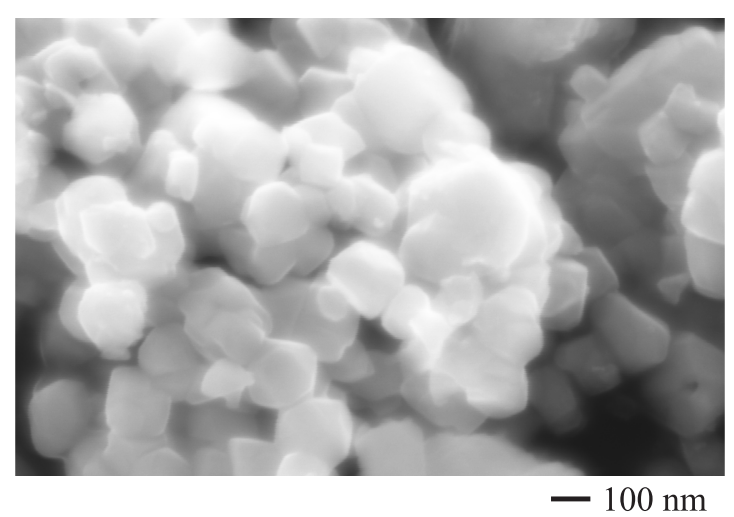

Pис. 9. SEM-изображение порошка $\mathrm{BaTiO}_{3}$, отожженного при температуре, равной $400^{\circ} \mathrm{C}$, в течение $16 \mathrm{~h}$.

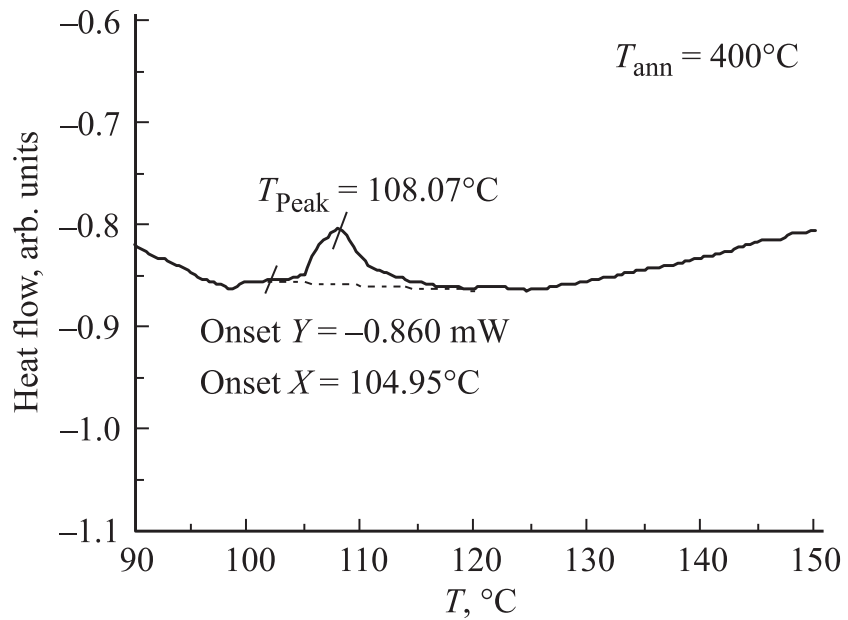

Рис. 10. Детализированная DSC-кривая, полученная от исходного порошка титаната бария, отожженного при температуре $400^{\circ} \mathrm{C}$ в течение $16 \mathrm{~h}$.

контрасту кристаллиты с огранкой, близкой к кубической. Одновременно широкая DSC-кривая, характерная для кратковременных отжигов исходного порошка при температурах $500-800^{\circ} \mathrm{C}$ (см. рис. 5), трансформировалась в DSC-кривую, характерную для микропорошков $\mathrm{BaTiO}_{3}$ (см. рис. 7). Кроме того, положение пикового значения DSC-кривой, характеризующее температуру фазового перехода, сместилось в низкотемпературную область. Последнее соответствует диаграмме состояния температур фазовых переходов от размера кристаллитов, представленных в классической работе [21]. Таким образом, наряду с известным влиянием размера кристаллитов на температуры и кинетику фазовых переходов в титанате бария значительную роль на параметры переходов играет и совершенство структуры отдельных кристаллитов.

3.2. Структурные изменения в прессованных таблетках $\mathrm{BaTiO}_{3}$. Вторая часть нашего исследования посвящена структурным изменениям в образцах $\mathrm{BaTiO}_{3}$, спрессованных в таблетки при комнатной температуре при максимальной нагрузке, равной $6.4 \cdot 10^{3} \mathrm{~kg} / \mathrm{cm}^{2}$, на установке INSTRON и отожженных при повышенных температурах. Дифракционные спектры таких таблеток, отожженных по описанной в разд. 2 методике при температурах $600-900^{\circ} \mathrm{C}$, не имели заметных отличий от дифракционных спектров для порошков при тех же условиях отжига. Однако повышение температуры отжига таблеток до $1200^{\circ} \mathrm{C}$ привело к кардинальному изменению дифракционных спектров по отношению к спектрам для порошков, также отожженных при $1200^{\circ} \mathrm{C}$. Основные результаты рентгеновских дифракционных исследований таблеток отображены на рис. 11. Спектр (a) относится к порошкообразному образцу, отожженному при $1200^{\circ} \mathrm{C}$ в течение $3.5 \mathrm{~h}$. Сравнение этого спектра со спектром исходного порошка, зарегистрированного при комнатной 


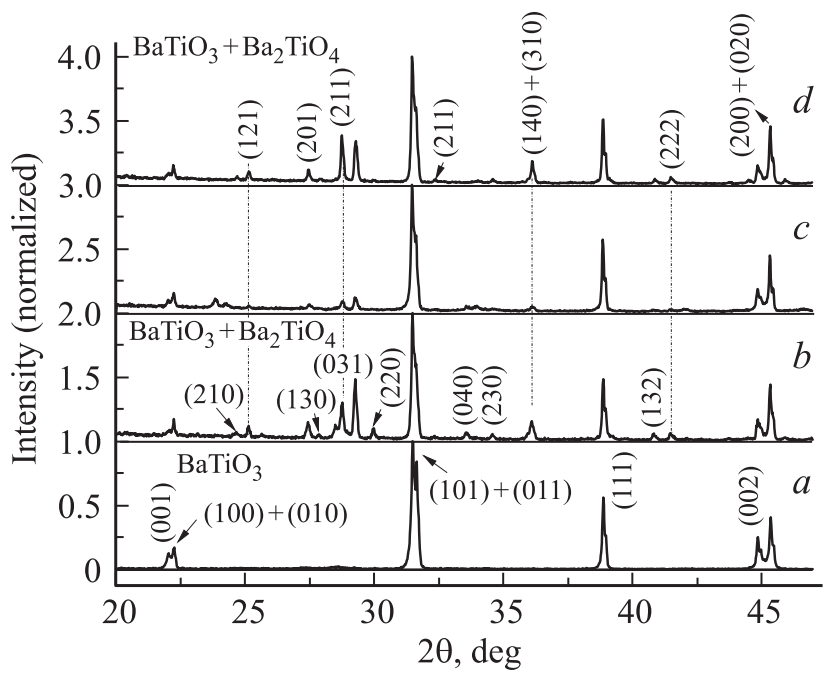

Рис. 11. Рентгеновские дифракционные спектры образцов $\mathrm{BaTiO}_{3}$, испытавших различные последовательности отжигов: (a) - исходный порошок, отожженный при $T=1200^{\circ} \mathrm{C}$ в течение $3.5 \mathrm{~h} ;(b)$ - таблетка $\mathrm{BaTiO}_{3}$, отожженная при $T=1200^{\circ} \mathrm{C}$ в течение $3.5 \mathrm{~h} ;(c)$ - таблетка $\mathrm{BaTiO}_{3}$, отожженная при $T=1200^{\circ} \mathrm{C}$ в течение $3.5 \mathrm{~h}$, затем дополнительно отожжена сначала при $700^{\circ} \mathrm{C}$ в течение $14 \mathrm{~h}$ и затем при $600^{\circ} \mathrm{C}$ в течение $16 \mathrm{~h} ;(d)$ - таблетка $\mathrm{BaTiO}_{3}$, отожженная как в пункте $(c)$, затем дополнительно отожжена при $1200^{\circ} \mathrm{C}$ в течение $3.5 \mathrm{~h}$.

температуре (см. рис. 1,a), показывает, что все рефлексы, кроме отражения (111), расщеплены на две компоненты, что является указанием принадлежности структуры к тетрагональной фазе титаната бария. Параметры решетки отожженного образца равны $a=4.0009 \AA$ и $c=4.0369 \AA$ А соответственно $(c / a=1.0106)$.

Совершенно другая ситуация наблюдается для таблетки, отожженной при $1200^{\circ} \mathrm{C}$ в течение $3.5 \mathrm{~h}$, спектр $(b)$. Кроме рефлексов, принадлежащих тетрагональной фазе $\mathrm{BaTiO}_{3}$, имеется большое число рефлексов, которые индицируются как принадлежащие орторомбической фазе $\mathrm{Ba}_{2} \mathrm{TiO}_{4}$ (S.G. Pnam (62), $a=7.6514 \AA, b=10.5502 \AA, c=6.1059 \AA)$ [22]. Видно, что пиковая интенсивность рефлексов $\mathrm{Ba}_{2} \mathrm{TiO}_{4}$ при этом сравнима с пиковой интенсивностью рефлексов $\mathrm{BaTiO}_{3}$. Это означает, что процентная доля $\mathrm{Ba}_{2} \mathrm{TiO}_{4}$-фазы в таблетке довольно велика $\left(C_{\mathrm{Ba}_{2} \mathrm{TiO}_{4}} / C_{\mathrm{BaTiO}_{3}} \approx 23.5 / 76.5\right)$ и не может быть объяснена с позиции нарушения стехиометрического состава исходного порошка. ${ }^{1}$ Измерения концентраций Ва и Ті в исходном и отожженном при $1200^{\circ} \mathrm{C}$ порошках показали, что разброс состава от точки к точке от средней концентрации $C_{\mathrm{Ba}} / C_{\mathrm{Ti}}$, равной 1.00 , не превышало $1.0 \%$. Такое локальное отклонение состава, если и приведет к образованию фазы $\mathrm{Ba}_{2} \mathrm{TiO}_{4}$, интенсивность ее рефлексов на дифракционном спектре будет неотделима от фонового рассеяния.

\footnotetext{
${ }^{1}$ Определение процентного состава фаз осуществлялось с помощью программы PCW23 (PowderCell).
}

Более того, образовавшаяся в таблетках фаза оказалась термообратимой. Так, дополнительный длительный отжиг таблетки сначала при $700^{\circ} \mathrm{C}$ в течение $14 \mathrm{~h}$ и затем при $600^{\circ} \mathrm{C}$ в течение $16 \mathrm{~h}$ (см. рис. 11 спектр $(c)$ ) привел к кардинальному падению интенсивности рефлексов $\mathrm{Ba}_{2} \mathrm{TiO}_{4}$ (фактически к исчезновению новой фазы, $\left.C_{\mathrm{Ba}_{2} \mathrm{TiO}_{4}} / C_{\mathrm{BaTiO}_{3}} \approx 3 / 97\right)$, а повторный отжиг таблетки при $1200^{\circ} \mathrm{C}$ привел к восстановлению интенсивности рефлексов, полученных при первом отжиге, спектр $(d)$ на рис. 11 . Такая температурная обратимость интенсивности рефлексов новой фазы дает основание предположению о равновесном характере существования фазы $\mathrm{Ba}_{2} \mathrm{TiO}_{4}$ в матрице $\mathrm{BaTiO}_{3}$.

Возникает два вопроса: в каких местах зарождается фаза $\mathrm{Ba}_{2} \mathrm{TiO}_{4}$ и какова причина зарождения фазы $\mathrm{Ba}_{2} \mathrm{TiO}_{4}$ ? Предполагаемым местом зарождения могли бы быть межзеренные границы, образовавшиеся после компактирования порошка в таблетки. Такое предположение легко проверяется методами сканирующей электронной микроскопии. На рис. 12 показан набор SEM-изображений различных участков поверхности таблетки. Изображения $(a)$ и $(b)$ отличаются друг от друга только коэффициентом увеличения. Хорошо видно, что межзеренные границы очень узкие и, хотя вдоль границ расположены некие неизвестные частички, их суммарный объем очень мал, чтобы дать на дифракционном спектре рефлексы фазы $\mathrm{Ba}_{2} \mathrm{TiO}_{4}$ заметной интенсивности. Таким образом, приведенные SEM-изображения не позволяют сделать заключение о расположении $\mathrm{Ba}_{2} \mathrm{TiO}_{4}$-фазы в межзеренных границах.

На рис. 12, $c, d$ показаны SEM-изображения другой области поверхности таблетки, на которой хорошо виден полосчатый контраст индивидуальных зерен. Подобный контраст, в принципе, может характеризовать двойниковую структуру, а именно „, $a^{\text {“ }}$ и „, $c^{\text {с }}$ домены, известные для тетрагональной фазы титаната бария. Такое предположение согласуется с наличием на дифракционных спектрах, приведенных на рис. $11, b, c, d$, отражений $(h 00)$ и $(00 l)$, которым отвечают разные межплоскостные расстояния, определяющие гофрированный характер поверхности таблетки, отображенный на SEM-изображениях.

С другой стороны, полосчатый контраст мог бы быть обусловлен и ламинарным расположением фаз $\mathrm{BaTiO}_{3}$ и $\mathrm{Ba}_{2} \mathrm{TiO}_{4}$. На рис. 13 показаны SEM-изображения и распределение вдоль выделенных линий сканирования концентрации атомов $\mathrm{Ba}$, Ti и $\mathrm{O}$ для участков поверхности таблетки с зернами без полосчатого контраста изображения и с полосчатым контрастом изображения. Хорошо видно, что в обоих случаях распределение атомов Ва и Ті соответствует однородному распределению вдоль направления сканирования. В то же время распределение кислорода заметно отличается от распределения бария и титана, причем отличие наиболее существенно в приграничных областях зерен. Необычным является то, что измеренный в нескольких участках поверхности таблетки элементный со- 


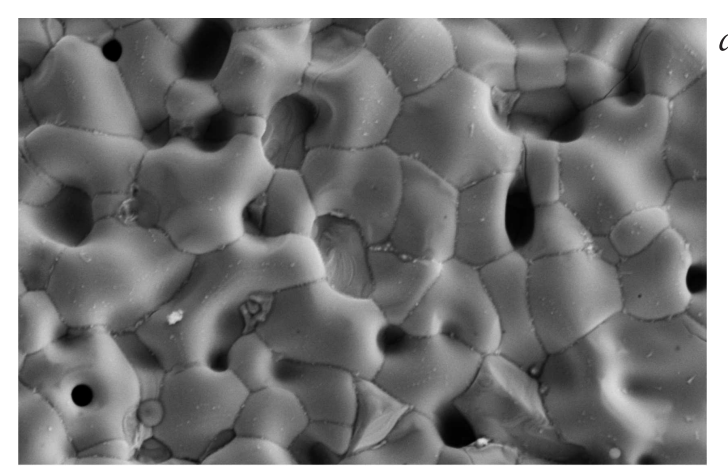

$-3 \mu \mathrm{m}$

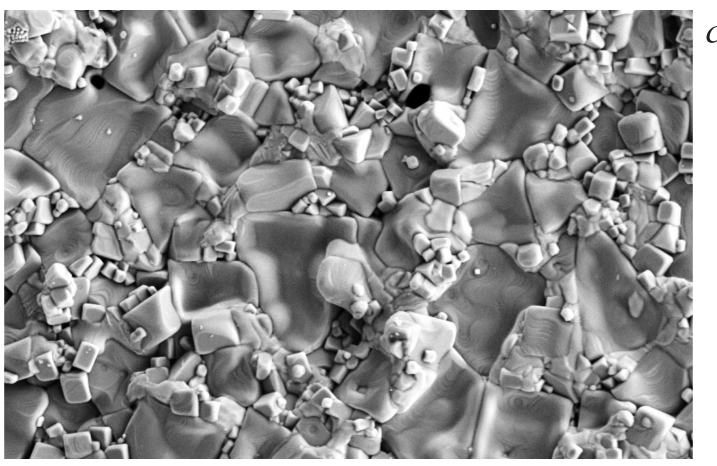

$-3 \mu \mathrm{m}$

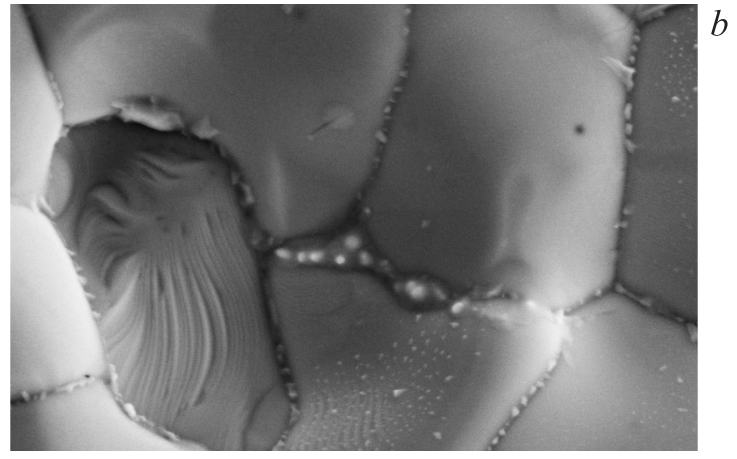

$-1 \mu \mathrm{m}$

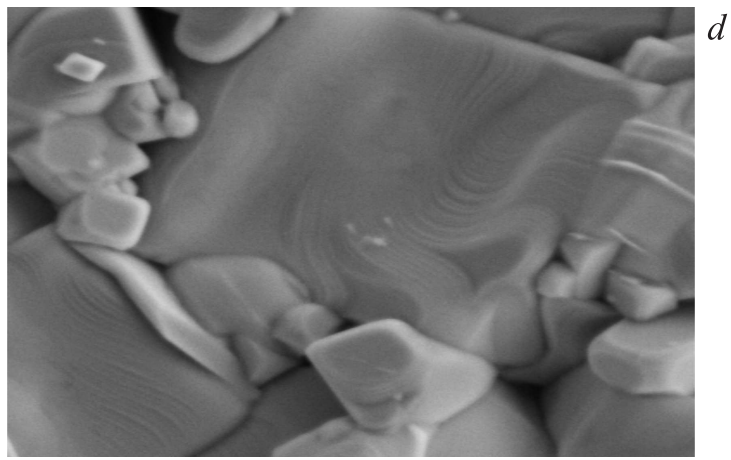

Рис. 12. SEM-изображения разных участков поверхности таблетки $\mathrm{BaTiO}_{3}$, отожженной при $1200^{\circ} \mathrm{C}$ в течение $3.5 \mathrm{~h}$ : $(a)$ и (b) - изображения участков поверхности, имеющих „гладкий“ контраст кристаллитов, и отличающиеся размером области сканирования и коэффициентом увеличения; $(c)$ и $(d)$ - изображения участков поверхности таблетки, имеющих полосчатый контраст индивидуальных зерен. Масштаб $(d)$-изображения в 3 раза больше масштаба $(c)$-изображения.

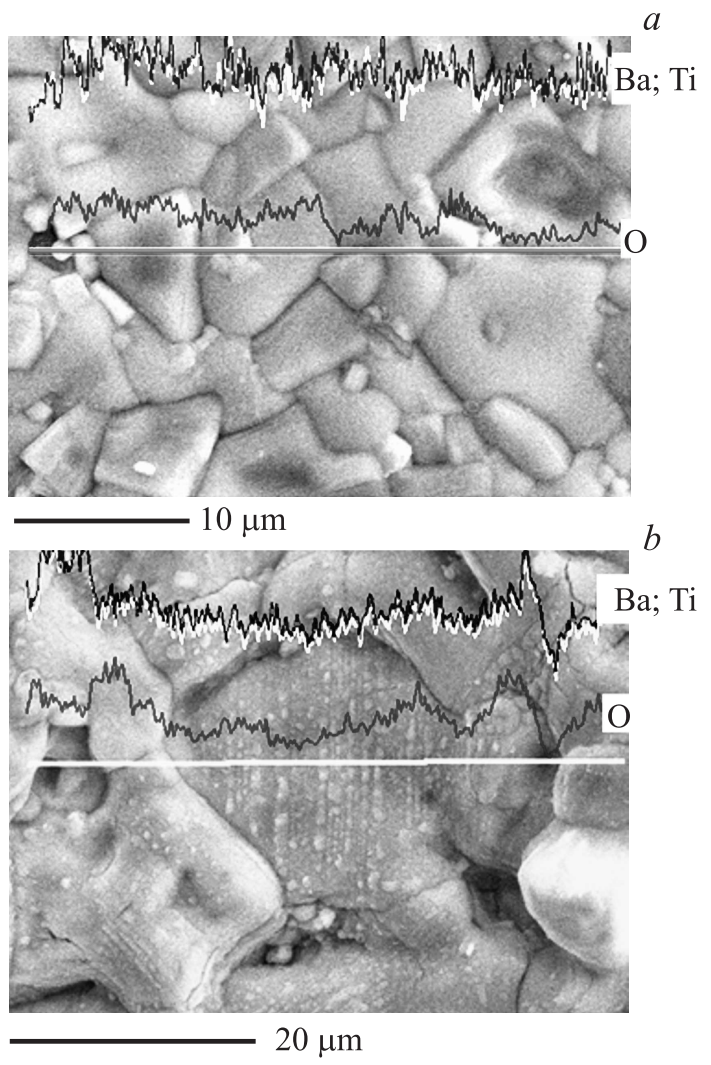

Рис. 13. SЕМ-изображение участков поверхности таблетки $\mathrm{BaTiO}_{3}$, состав которых отображен в табл. 1 и 2. став для „Гладкой поверхности“ зерен соответствует соединению, близкому $\mathrm{Ba}_{2} \mathrm{TiO}_{4}$ (см. табл. 1), а для участков с полосчатым контрастом элементный состав близок к $\mathrm{BaTiO}_{3}$, но с превышением атомов титана над концентрацией бария $\sim 5.6 \%$ (см. табл. 2$)^{2}$. Полученные результаты дают основание считать, что полосчатый контраст отображает двойниковую структуру титаната бария, а однородный, гладкий контраст соответствует зернам, состоящим только из фазы $\mathrm{Ba}_{2} \mathrm{TiO}_{4}$.

Интересно, что для порошкообразного образца, отожженного при тех же условиях, что и таблетка, и состоящего из ограненных кристаллитов (см. рис. 14), состав строго соответствует фазе $\mathrm{BaTiO}_{3}$ (см. табл. 3). Более того, для участков поверхности таблетки, которые по каким-то причинам не подверглись прессованию, рельеф поверхности после отжига соответствует рельефу порошкообразного образца, сохраняя огранку отдельных кристаллитов (см. рис. 15), и сохраняя состав $\mathrm{BaTiO}_{3}$ (см. табл. 4).

Полученные результаты являются весьма необычными. Оказалось, что в случае прессования нанопорошка $\mathrm{BaTiO}_{3}$ и последующего отжига полученной таблетки

\footnotetext{
${ }^{2}$ Обратим внимание, что глубина проникновения рентгеновских лучей при дифракции и при измерении элементного состава приблизительно одна и та же и составляет $\sim 5-10 \mu \mathrm{m}$.
} 
при высоких температурах новая фаза $\mathrm{Ba}_{2} \mathrm{TiO}_{4}$ образуется не в межзеренных границах, как ожидалось, а образует отдельные зерна, значительно превышающие по размеру кристаллиты исходного нанопорошка. Это означает, что перемещение атомов бария для образования фазы $\mathrm{Ba}_{2} \mathrm{TiO}_{4}$ осуществляется на макроскопические расстояния не только по отношению к межячеечному расстоянию, но и по отношению к размерам исходных нанокристаллитов.

Таблица 1. Атомный состав участка поверхности таблетки, отображенной на рис. 13, a

\begin{tabular}{c|r|r}
\hline \multirow{2}{*}{ Элемент } & \multicolumn{2}{|c}{ Содержание } \\
\cline { 2 - 3 } & $\mathrm{wt} \%$ & at $\%$ \\
\hline $\mathrm{O}$ & 22.65 & 55.23 \\
$\mathrm{Ti}$ & 11.69 & 11.41 \\
$\mathrm{Ba}$ & 65.66 & 22.36 \\
Всего & 100.00 & 100.00
\end{tabular}

Таблица 2. Атомный состав участка поверхности таблетки, отображенной на рис. 13, $b$

\begin{tabular}{c|r|r}
\hline \multirow{2}{*}{ Элемент } & \multicolumn{2}{|c}{ Содержание } \\
\cline { 2 - 3 } & wt \% & at \% \\
\hline O & 16.99 & 53.55 \\
$\mathrm{Ti}$ & 23.27 & 24.51 \\
$\mathrm{Ba}$ & 59.74 & 21.94 \\
Всего & 100.00 & 100.00
\end{tabular}

Таблица 3. Атомный состав порошка, отожженного при $1200^{\circ} \mathrm{C}$ в течение $3.5 \mathrm{~h}$ (см. рис. 14)

\begin{tabular}{c|r|r}
\hline \multirow{2}{*}{ Элемент } & \multicolumn{2}{|c}{ Содержание } \\
\cline { 2 - 3 } & $\mathrm{wt} \%$ & at \% \\
\hline $\mathrm{O}$ & 26.78 & 67.84 \\
$\mathrm{Ti}$ & 19.14 & 16.20 \\
$\mathrm{Ba}$ & 54.08 & 15.96 \\
Всего & 100.00 & 100.00
\end{tabular}

Таблица 4. Атомный состав поверхности таблетки $\mathrm{BaTiO}_{3}$, на которой видны отдельные ограненные кристаллиты (см. рис. 15)

\begin{tabular}{c|r|r}
\hline \multirow{2}{*}{ Элемент } & \multicolumn{2}{|c}{ Содержание } \\
\cline { 2 - 3 } & $\mathrm{wt} \%$ & at \% \\
\hline $\mathrm{O}$ & 18.90 & 56.98 \\
$\mathrm{Ti}$ & 22.16 & 22.32 \\
$\mathrm{Ba}$ & 58.94 & 20.71 \\
Всего & 100.00 & 100.00
\end{tabular}

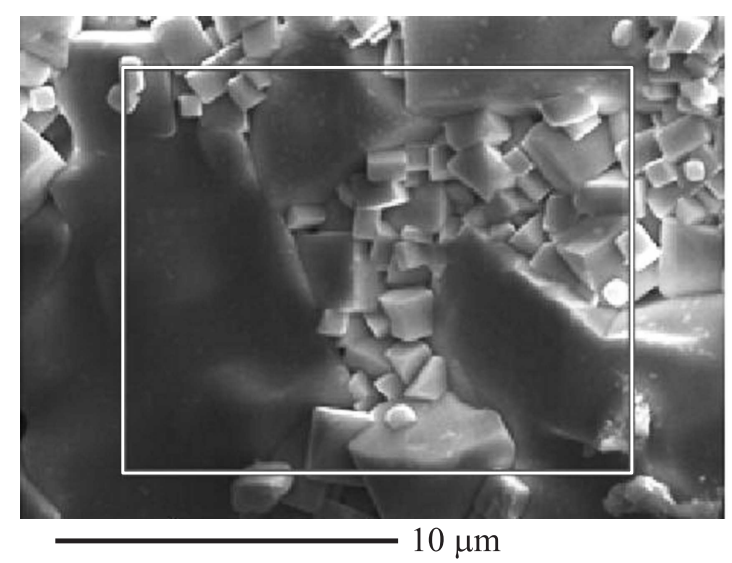

Рис. 14. SEM-изображение участка поверхности порошкообразного образца $\mathrm{BaTiO}_{3}$, состав которого отображен в табл. 3 .

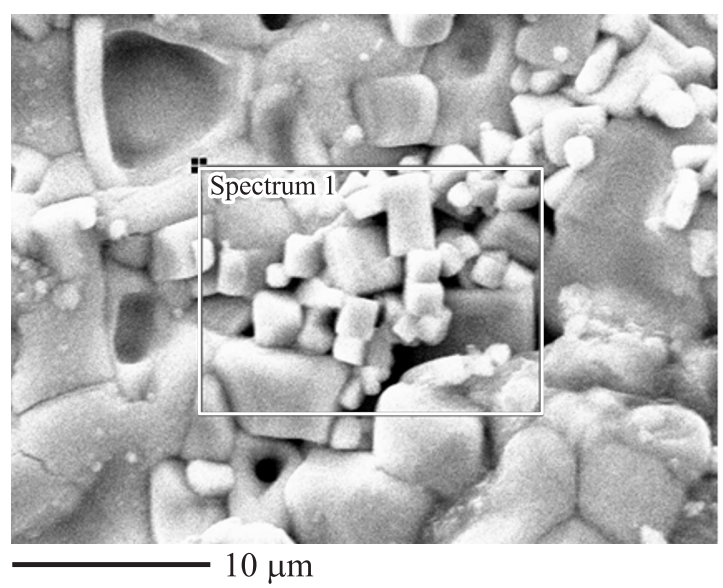

Рис. 15. SEM-изображение участка поверхности таблетки $\mathrm{BaTiO}_{3}$, на котором видны отдельные ограненные кристаллиты и состав которых отображен в табл. 4.

Для ответа на вопрос о природе двухфазного состояния обратим внимание на процесс образования $\mathrm{BaTiO}_{3}$. Промышленный метод получения титаната бария основывается на твердофазной реакции между $\mathrm{BaCO}_{3}$ и $\mathrm{TiO}_{2}$ при температуре порядка $1200^{\circ} \mathrm{C}$. Эта реакция описывается как

$$
\mathrm{BaCO}_{3}+\mathrm{TiO}_{2} \rightarrow \mathrm{BaTiO}_{3}+\mathrm{CO}_{2} \uparrow .
$$

Однако эта реакция идет не прямо, а через образование промежуточной фазы $\mathrm{Ba}_{2} \mathrm{TiO}_{4}$. Вопросу образования титаната бария через фазу $\mathrm{Ba}_{2} \mathrm{TiO}_{4}$ посвящены многочисленные исследования [23-36]. Основной вывод, сделанный по результатам изучения образования $\mathrm{BaTiO}_{3}$ на воздухе в работах [24,28-31], следующий. На первых этапах синтеза сначала образуется небольшое количество $\mathrm{BaTiO}_{3}$ непосредственно из $\mathrm{BaCO}_{3}$ и $\mathrm{TiO}_{2}$ (rutile). Затем образовавшийся титанат бария реагирует с избытком $\mathrm{BaCO}_{3}$ по реакции

$$
\mathrm{BaCO}_{3}+\mathrm{BaTiO}_{3} \rightarrow \mathrm{Ba}_{2} \mathrm{TiO}_{4}+\mathrm{CO}_{2} \uparrow .
$$


Затем все повторяется, пока не закончится $\mathrm{BaCO}_{3}$. Наконец $\mathrm{Ba}_{2} \mathrm{TiO}_{4}$ взаимодействует с остатками $\mathrm{TiO}_{2}$, окончательно образуя $\mathrm{BaTiO}_{3}$ :

$$
\mathrm{Ba}_{2} \mathrm{TiO}_{4}+\mathrm{TiO}_{2} \rightarrow 2 \mathrm{BaTiO}_{3}
$$

Исходя из допущения, что реакция (3) имеет обратимый характер

$$
\mathrm{Ba}_{2} \mathrm{TiO}_{4}+\mathrm{TiO}_{2} \leftrightarrow 2 \mathrm{BaTiO}_{3}
$$

и равновесное состояние зависит от температуры отжига, можно объяснить представленные нами результаты рентгеновских исследований. Так, если равновесное состояние при $600^{\circ} \mathrm{C}$ сдвинуто в правую сторону уравнения $(3)^{\prime}$, то избыток $\mathrm{TiO}_{2}$ в зернах $\mathrm{BaTiO}_{3}$, обнаруженный нами ранее, при длительном отжиге может диффундировать в зерна $\mathrm{Ba}_{2} \mathrm{TiO}_{4}$, приводя к увеличению доли фазы $\mathrm{BaTiO}_{3}$ за счет уменьшения доли фазы $\mathrm{Ba}_{2} \mathrm{TiO}_{4}$. При повышении температуры отжига до $1200^{\circ} \mathrm{C}$ равновесие в реакции $(3)^{\prime}$ сдвигается влево, приводя к росту процентного содержания фазы $\mathrm{Ba}_{2} \mathrm{TiO}_{4}$, что и наблюдается в эксперименте.

Остается последний и самый важный вопрос: почему в таблетках образуется $\mathrm{Ba}_{2} \mathrm{TiO}_{4}$, а в порошках при тех же режимах отжига не образуется? Для объяснения этого факта можно воспользоваться интересными результатами экспериментов [37-40] по синтезу $\mathrm{BaTiO}_{3}$ в вакууме и на воздухе. Ими был проведен эксперимент, в котором на монокристальную подложку $\mathrm{TiO}_{2}$ напыляли тонкий слой $\mathrm{BaCO}_{3}$ при температуре $575^{\circ} \mathrm{C}$. При этой температуре никакого взаимодействия $\mathrm{BaCO}_{3}$ с подложкой не происходило. Затем полученная планарная система отжигалась при повышенных температурах $\left(T_{\mathrm{ann}}>600-650^{\circ} \mathrm{C}\right)$. Оказалось, что при отжигах в вакууме (парциальное давление $\mathrm{CO}_{2}\left(P_{\mathrm{CO}_{2}}\right)<1 \cdot 10^{-5} \mathrm{mbar}$ ) образуется промежуточная фаза $\mathrm{Ba}_{2} \mathrm{TiO}_{4}$, а при отжиге на воздухе $\left(\mathrm{P}_{\mathrm{CO}_{2}}<0.381 \mathrm{mbar}\right)$ ее образования не происходит. Авторы объяснили это явление изменением свободной энергии Гиббса реакции от давления газовой среды, в которой происходит твердофазная реакция.

Какое отношение имеет этот результат к нашему исследованию? Прежде всего отметим, что в нашем случае фаза $\mathrm{BaTiO}_{3}$ изначально уже сформирована и, следовательно, при ее высокотемпературном отжиге все последующие превращения начинаются с разложения $\mathrm{BaTiO}_{3}$ по реакции

$$
\mathrm{BaTiO}_{3} \rightarrow \mathrm{BaO}+\mathrm{TiO}_{2} .
$$

В условиях таблетки количество $\mathrm{CO}_{2}$, находящегося в порах прессованного вещества, незначительно, и ее присутствие не может помешать накоплению окиси бария и образованию фазы $\mathrm{Ba}_{2} \mathrm{TiO}_{4}$ по реакции

$$
2 \mathrm{BaO}+\mathrm{TiO}_{2} \rightarrow \mathrm{Ba}_{2} \mathrm{TiO}_{4} .
$$

При высокотемпературном отжиге порошка титаната бария на воздухе все наночастицы вещества легко доступны находящемуся в воздухе углекислому газу, который энергично реагирует с $\mathrm{BaO}$, образуя карбонат бария по реакции

$$
\mathrm{BaO}+\mathrm{CO}_{2}>\mathrm{BaCO}_{3} .
$$

$\mathrm{B}$ свою очередь $\mathrm{BaCO}_{3}$ взаимодействует с продуктом разложения (4), а именно с $\mathrm{TiO}_{2}$, восстанавливая на поверхности $\mathrm{BaTiO}_{3}$. Далее все повторяется: снова идет разложение (4), затем взаимодействие $\mathrm{BaO}$ с углекислым газом с образованием $\mathrm{BaCO}_{3}$ и, наконец, снова реакция (1). В итоге такого цикла превращений, происходящих в тонком приповерхностном слое кристаллитов, разложение (4) не проникает в объем кристаллитов, сохраняя в нем исходную структуру $\mathrm{BaTiO}_{3}$.

Можно также предположить альтернативную модель. Как уже отмечалось во введении, для простых оксидов редкоземельных элементов прессование наноскопических порошков приводит к образованию в таблетках в межграничных областях высокотемпературных фаз при заведомо более низких температурах, нежели в порошках [17]. Имея в виду, что в процессе прессования нанопорошка титаната бария образуется большое количество межкристаллитных границ с повышенной энергией (так как над системой была произведена работа), средний химический потенциал системы после прессования значительно увеличивается и, значит, при той же температуре отжига, что и порошка, таблетка эффективно находится как бы при более высокой температуре, что позволяет осуществиться реакции разложения (4) для таблетки, но не для порошка. При последующем охлаждении таблетки осуществляется реакция (5) образования $\mathrm{Ba}_{2} \mathrm{TiO}_{4}$, а порошок остается в том же состоянии $\mathrm{BaTiO}_{3}$, в котором он находился при отжиге. Это и объясняет сильное различие в структурном состоянии прессованных таблеток и порошкообразных образцов. В принципе такому заключению имеются определенные подтверждения. Так, наличие на SEM-изображениях поверхности таблеток областей, обогащенных $\mathrm{Ba}_{2} \mathrm{TiO}_{4}$, областей с тем же масштабом зерен, но содержащих только $\mathrm{BaTiO}_{3}$, и областей, на которых виден набор отдельных ограненных кристаллитов $\mathrm{BaTiO}_{3}$ (см. рис. 12-15 и табл. 1-4), указывает на то, что распределение плотности порошка в цилиндре для прессования было неравномерным вдоль поверхности. Это привело к тому, что одни области были сжаты сильнее других. В них при отжиге протекала реакция (4) и по реакции (5) соответственно образовывался $\mathrm{Ba}_{2} \mathrm{TiO}_{4}$. В других областях уровень сжатия и, следовательно, химический потенциал были меньше, что не приводило к протеканию реакции (4), сохраняя фазу $\mathrm{BaTiO}_{3}$, но позволяя провести значительный рост кристаллитов. В локальных областях, в которых прессования совсем не произошло (см. рис. 15), химический потенциал был таким же, как и в порошке, что и привело к образованию ограненных кристаллитов. Ясно, что для однозначного выбора модели процесса необходимы дополнительные исследования. В частности, интересно провести аналогичные исследования изменения фазового состава от уровня механической нагрузки 
при прессовании для разного размера кристаллитов, а при заданных размерах кристаллитов и уровне нагрузки - от температуры отжига. Для порошков желательно провести исследования при разных температурах in situ в вакуумной рентгеновской камере.

Эти эксперименты планируются нами в последующих исследованиях.

\section{4. Заключение}

В заключение отметим основные результаты:

1) показано, что для нанопорошков титаната бария температура перехода из тетрагональной фазы в кубическую зависит не только от размера кристаллитов, но и в значительной степени от их структурного совершенства;

2) обнаружено, что отжиг при высоких температурах $\left(T>1000^{\circ} \mathrm{C}\right)$ прессованных при комнатной температуре в таблетки нанопорошков $\mathrm{BaTiO}_{3}$ приводит к образованию в них двухфазного состояния со значительной долей фазы $\mathrm{Ba}_{2} \mathrm{TiO}_{4}$, а такой же отжиг свободных от прессования порошков приводит только к росту кристаллитов титаната бария;

3) установлено, что такое двухфазное состояние является равновесным - при понижении температуры отжига фаза $\mathrm{Ba}_{2} \mathrm{TiO}_{4}$ фактически исчезает, а при повышении восстанавливается вновь;

4) предложены два гипотетических механизма образования фазы $\mathrm{Ba}_{2} \mathrm{TiO}_{4}$ в прессованных таблетках и ее отсутствия в свободных порошках $\mathrm{BaTiO}_{3}$. Первый механизм основан на изменении свободной энергии Гиббса от давления газовой среды, в которой происходит твердофазная реакция, и различии давления газообразного $\mathrm{CO}_{2}$ в порошке на воздухе и внутри спрессованной таблетки. Второй механизм учитывает увеличение химического потенциала в таблетке за счет энергии межкристаллитных границ после прессования. Вследствие этого реакции при высоких температурах отжига в таблетках и порошке протекают различно.

Авторы выражают искреннюю благодарность В.В. Синицыну за помощь в проведении калориметрических измерений и Е.Ю. Постновой за проведение SEM-анализа.

\section{Список литературы}

[1] I.M. Shmytko, G.K. Strukova, E.A. Kudrenko. Crystallography Rep. 51, Suppl. 1, S163 (2006).

[2] I.M. Shmytko, E.A. Kudrenko, G.K. Strukova. JETP Lett. 86, 474 (2007).

[3] Е.А. Кудренко, И.М. Шмытько, Г.К. Струкова. ФТТ 50, 924 (2008).

[4] И.М. Шмытько, Е.А. Кудренко, Г.К. Струкова, Н.В. Классен. ФТТ 50, 1108 (2008).

[5] И.М. Шмытько, Г.К. Струкова. ФТТ 51, 1796 (2009).

[6] И.М. Шмытько, Е.А. Кудренко, Г.К. Струкова. ФТТ 51, 1834 (2009).

[7] I. Shmytko, G. Strukova, E. Kudrenko. Acta Cryst. A 66, 230 (2010).
[8] В.В. Кедрин, И.М. Шмытько. ФТТ 57, 295 (2015).

[9] I. Shmytko. Acta Cryst. A 67, 533 (2011).

[10] V. Kedrov, I.M. Shmyt'ko, S.Z. Shmurak, E.A. Kudrenko, N.V. Klassen. J. Mater. Res. 27, 2117 (2012).

[11] И.М. Шмытько, И.Н. Кирякин, Г.К. Струкова. ФТТ 53, 353 (2011).

[12] E.A. Kudenko, I.M. Shmytko, G.K. Strukova. Acta cryst. A 64, C427 (2008).

[13] I.M. Shmytko, E.A. Kudrenko, G.K. Strukova, V.V. Kedrov, N.V. Klassen. Z. Kristallogr. Suppl. 27, 211 (2008).

[14] E.A. Kudrenko, I.M. Shmytko, V.V. Synytzin, E.G. Ponyatovsky, B.S. Red'kin. Z. Kristallogr. Suppl. 27, 205 (2008).

[15] И.М. Шмытько, И.Н. Кирякин, Г.К. Струкова. ФТТ 55, 1364 (2013).

[16] И.М. Шмытько, И.Н. Кирякин, Г.К. Струкова. ФТТ 55, 1369 (2013).

[17] И.М. Шмытько, Г.Р. Ганеева, А.С. Аронин. ФТТ 57129 (2015).

[18] D.E. Race, R. Roy. J. Amer. Ceram. Soc. 38, 102 (1955).

[19] G.K. Williamson, W.H. Hall. Acta Metall. 1, 22 (1953).

[20] M.B. Smith, K. Page, Th. Siegrist, P.L. Redmond, E.C. Walter, R. Seshadri, L.E. Brus, M.L. Steigerwald. J. Am. Chem. Soc. 130, 6955 (2008).

[21] A.V. Polotai, A.V. Ragulya, C.A. Randall. Ferroelectrics 288, 93 (2003).

[22] H. McMurdie, M. Morris, E. Evans, B. Paretzkin, W. Wong-Ng, Y. Zhang. Powder Diffraction 2, 44 (1987).

[23] A. Beauger, J.C. Mutin, J.C. Niepce. J. Mater. Sci. 19, 195 (1984).

[24] W. Trzebiatowski, J. Wojciechowska, J. Damm. Experientia 6, 138 (1950).

[25] W. Trzebiatowski, J. Wojciechowska, J. Damm. Roczniki Chem. 26, 12 (1952).

[26] T. Kubo, K. Shinriki. J. Chem. Soc. Jpn. Ind. Chem. Sect. 55, 49 (1952).

[27] T. Kubo, K. Shinriki. J. Chem. Soc. Jpn, Ind. Chem. Sect. 55, 137 (1952).

[28] T. Kubo, K. Shinriki. J. Chem. Soc. Jpn, Ind. Chem. Sect. 57, 612 (1954).

[29] W. Freundlich. C. R. Acad. Sci. 236, 1895 (1953).

[30] P. Turlier, L. Eyraud, C. Eyraud, M. Prettre. C. R. Acad. Sci. 246, 422 (1958).

[31] L.K. Templeton, J.A. Pask. J. Am. Ceram. Soc. 42, 212 (1959).

[32] Y. Suyama, A. Kato. Ceramurgia Int. 1, 5 (1975).

[33] M. Cournil, M. Soustelle, G. Thomas. Oxid. Met. 13, 77 (1979).

[34] M. Cournil, M. Soustelle, G. Thomas. Oxid. Met. 13, 89 (1979).

[35] A. Beauger, J.C. Mutin, J.C. Niepce. J. Mater. Sci. 18, 3041 (1983).

[36] A. Beauger, J.C. Mutin, J.C. Niepce. J. Mater. Sci. 18, 3543 (1983).

[37] A. Lotnyk, S. Senz, D. Hesse. Solid State Ionics 177, 429 (2006).

[38] A. Lotnyk, S. Senz, D. Hesse. Acta Mater. 55, 2671 (2007).

[39] A. Lotnyk, S. Senz, D. Hesse. Diffusion Fundamentals 2, 51.1 (2005).

[40] A. Lotnyk. Solid state reactions in electroceramic systems, Dissertation / Martin-Luther-Universität Halle-Wittenberg, (2007). P. 119. 